
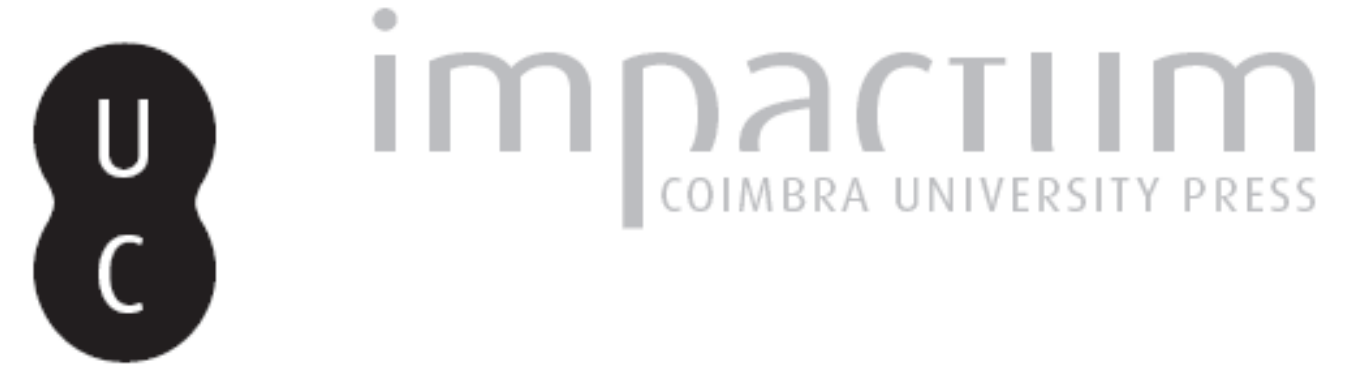

\title{
Representações de áreas de riscos sócio-ambientais: geomorfologia e ensino
}

Autor(es): $\quad$ Souza, Carla Juscélia de Oliveira; Oliveira, Janete Regina de

Publicado por: Associação Portuguesa de Riscos, Prevenção e Segurança

URL persistente:

URI:http://hdl.handle.net/10316.2/36058

DOI:

DOI:http://dx.doi.org/10.14195/1647-7723_18_15

Accessed : $\quad$ 26-Apr-2023 13:19:06

A navegação consulta e descarregamento dos títulos inseridos nas Bibliotecas Digitais UC Digitalis, UC Pombalina e UC Impactum, pressupõem a aceitação plena e sem reservas dos Termos e Condições de Uso destas Bibliotecas Digitais, disponíveis em https://digitalis.uc.pt/pt-pt/termos.

Conforme exposto nos referidos Termos e Condições de Uso, o descarregamento de títulos de acesso restrito requer uma licença válida de autorização devendo o utilizador aceder ao(s) documento(s) a partir de um endereço de IP da instituição detentora da supramencionada licença.

Ao utilizador é apenas permitido o descarregamento para uso pessoal, pelo que o emprego do(s) título(s) descarregado(s) para outro fim, designadamente comercial, carece de autorização do respetivo autor ou editor da obra.

Na medida em que todas as obras da UC Digitalis se encontram protegidas pelo Código do Direito de Autor e Direitos Conexos e demais legislação aplicável, toda a cópia, parcial ou total, deste documento, nos casos em que é legalmente admitida, deverá conter ou fazer-se acompanhar por este aviso. 


\section{territorium}

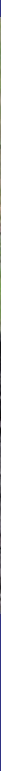

\section{Afirmar as Ciências Cindínicas}

Revista da Associação Portuguesa de Riscos, Prevenção e Segurança 
Carla Juscélia de Oliveira Souza

Curso de Geografia e Análise Ambiental Centro Universitário de Belo Horizonte - UNIBH carlaju@uol.com.br

Janete Regina de Oliveira Departamento de Geografia Universidade Federal de Viçosa - UFV janete.oliveira@ufv.br

\section{RESUMO}

O artigo discute a importância de se entender a dinâmica e os condicionantes dos movimentos de massa, a fim de se trabalhar com comunidades de áreas de risco ou em projetos de prevenção, por meio da educação, utilizando o recurso maquete. 0 processo de conhecimento dos movimentos de massa ocorre durante oficinas de maquete realizadas como atividade prática da disciplina Geomorfologia, no Curso de Geografia, e como proposta de atividade de extensão universitária para professores de educação básica e/ou representantes comunitários.

Palavras chave: Área de risco, Movimento de Massa, Maquete, Ensino

\section{RESUMEN}

Representación de las zonas de riesgos socio-ambientales: la geomorfología y la educación - El artículo discute la importancia de comprender la dinámica y las limitaciones de los movimientos de masas con el fin de trabajar con las comunidades en zonas de riesgo o en proyectos de prevención, mediante la educación, utilizando el recurso maquete. El proceso de entender el movimiento de masas se produce durante modelo de talleres como una actividad práctica de la geomorfología tema, en el Curso de Geografía, y como una actividad propuesta de extensión universitaria para los profesores de educación básica y/ o representantes de la comunidad.

Palabras clave: Zona de riesgo, la Misa del Movimiento, modelo, Educación

\section{RESUMÉ}

La représentation des zones de risques socio-environnementaux: la géomorphologie et l'éducation - L'article discute de l'importance de comprendre la dynamique et les contraintes des mouvements de masse en vue de travailler avec les communautés dans les zones de risque ou de projets de prévention, par l'éducation, en utilisant le modèle de ressource. Le processus de compréhension du mouvement de masse se produit au cours d'ateliers organisés en tant que modèle de l'activité pratique de la géomorphologie sous réserve, dans le cours de géographie, et comme une activité proposée de l'extension universitaire des enseignants de l'éducation de base et / ou les représentants de la communauté.

Mots-clé: Zones à risque, Mouvement de masse, modèle, Éducation

\section{ABSTRACT}

Representation of areas of socio-environmental risks: geomorphology and education - The article discusses the value of understanding the dynamics and the facts of mass movements in order to work with communities in areas of risk or prevention projects, through education, using the resource model. The process of understanding the mass movement occurs during model workshops held as practical activity of the Geomorphology subject in Geography teaching, and as a proposed future activity for basic education as an extension aimed at teachers and / or community representatives.

Key words: Risk area, Mass Movement, model, Education

* O texto deste artigo corresponde à comunicação apresentada ao II Congresso Internacional de Riscos e VI Encontro Nacional, tendo sido submetido para revisão em 11-02-2010, tendo sido aceite para publicação em 16-07-2010.

Este artigo é parte integrante da Revista Territorium, $n .^{\circ} 18,2011$, ${ }^{\circledR}$ RIscos, ISBN: 0872- 8941. 


\section{Introdução}

Os fenômenos naturais, expressão da dinâmica e interação dos diferentes sistemas que compõem o sistema Terra, em variáveis escalas espacial e temporal, são visíveis aos homens e mulheres e são por muitos concebidos como processos de origem natural e/ou antrópica. Na atualidade, existem um rol de conhecimentos científicos e técnicos a respeito dos diferentes fenômenos naturais furacões, maremotos, tsunamis, terremotos, vulcanismo, inundações, movimentos de massa, tempestades e outros. Entre esses, os movimentos de massa, são estudados quanto aos seus condicionantes geológicos, geomorfológicos e antrópicos.

O número crescente de ocupações desordenadas em terrenos inadequados para a ocupação humana, somado ao número ascendente de ocorrências de movimentos de massas, reforça a necessidade de se pensar e discutir, também, a questão de áreas de risco-socioambientais, por intermédio de ações no campo da educação.

Quando movimentos de massa ocorrem e atingem seres humanos, pessoas são tomados por sentimentos de lamentação, de pesar, de tristeza e de indignação. A população, como expectadora, lamenta as perdas materiais e humanas e, possivelmente, questiona as possíveis causas e culpados. Nessa mistura de sentimentos e questionamentos levantam-se as dimensões ora física, ora social e ora econômica do evento. Estudiosos, técnicos e voluntários, interessados por esse fenômeno e seus efeitos, utilizam de seus conhecimentos na tentativa de entender e explicar o fenômeno, de apontar causas, possibilidades e alternativas.

Em prol das vítimas do fenômeno natural, ações e medidas são tomadas. Estas ações são plausivas e bem vindas, principalmente em momentos de intervenções rápidas e diretas. Mas, e depois? 0 efeito direto e rápido do fenômeno sobre os elementos do ambiente - pessoas, edificações, monumentos, árvores, vertentes, fundo de vales e outros - é aos poucos "naturalizado" com o cotidiano e a rotina que se estabelece no dia a dia das pessoas, da sociedade direta e indiretamente atingida. Nesse cotidiano, os conhecimentos técnicos, científicos e dos voluntários se voltam para suas especificidades e locais de origem, até outros fenômenos naturais se manifestarem, novamente, como expressão da interação dos diferentes sistemas que compõem o sistema Terra.

Diante esse quadro, que se faz presente em diferentes partes do mundo, em diferentes épocas do ano e em diferentes escalas espaciais e com diferentes frequência e intensidade, questiona-se: não seria a educação também um caminho para se entender e prevenirse dos possíveis efeitos e riscos das áreas de risco de movimentos de massa?
Questiona-se, nos casos de vivência em áreas de riscos de movimentos de massa e de inundações, os sujeitos atingidos pelos efeitos desses fenômenos não estariam em melhor situação, para entender e problematizar a respeito das áreas de risco sócio-ambiental, se compreendessem a dinâmica dos movimentos de massa, assim como os processos geográficos?

Acreditamos quesim, uma vez que o conhecimento significativo pode constituir uma importante ferramenta de defesa e de cobrança no convívio em sociedade, principalmente quando o sujeito encontra-se em áreas de risco sócio-ambiental. Quando não se compreende os processos e condicionantes dos movimentos de massa, os mesmos são atribuidos, geralmemte, à natureza ou a Deus, como uma fatalidade. Essa concepção naturaliza e conforma o fato.

De acordo com Ribeiro (1995), em estudo sobre o grau de vunerabilidade da população da Colina do Castelo de São Jorge, verifica-se que
“Nas representações e nas práticas sociais associadas aos desastres ainda prevalece um entendimento de que a explicação destes fenômenos, pelo menos na sua origem, assenta em processos sobretudo físicos e /ou metafísicos. Consideram-se assim os desastres como fenômenos externos e, portanto, não directamente imputáveis do ponto de vista da sua construção social. Contudo, é somente enquanto processo de cunho socialmente relevante que os desastres encontram pertinência analítica e explicativa” (M.RIBEIRO, 1995, p.6).

$\mathrm{Na}$ citação de RIBEIRO (1995), verifica-se que entre a aquela população existe a distinção dos efeitos dos fenômenos naturais como resultados de processos naturais externos à dimensão humana, sendo que o humano passa a fazer parte desse efeito quando atingido pelo fenômeno. Portanto, nas representações e práticas sociais, discutidas por RIBEIRO (1995), verificase na relação sociedade-natureza, a concepção de dinâmica social separada da dinâmica natural, somente aproximadas durante situações de desastres sociais.

Esse fato reforça a importância e necessiade de se pensar aspectos do espaço geográfico, por diferentes sujeitos que não só os técnicos ou cientistas, mas principalmente pela população local. Pensar, discutir e educar sobre aspectos do espaço geográfico é, também, um caminho complementar e auxiliar às medidas de planejamento, prevenção e técnica comuns para áreas de riscos sócio-ambientais.

Com base nas ideias apresentadas nos parágrafos acima, este texto apresenta e discute uma atividade acadêmica, atenta a questão de formação e educação sobre movimentos de massa, entre alunos de Geografia, na disciplina Geomorfologia Climática e Estrutural, do Curso de Geografia 
e Análise Ambiental do Centro Universitário de Belo Horizonte - UNIBH. Essa atividade, denominada de Oficina de Geomorfologia, fundamenta-se na ideia de aprendizagem significativa de David AusuBel (1956), no enfoque globalizador e no método globalizado de Antoni ZABALA (2002). A atividade compreende tanto a produção de maquete, como uma base territorial onde processos geográficos e geomorfológicos ocorrem de maneira integrada, quanto a construção do entendimento dos processos geomorfológicos e antrópicos que ocorrem em encostas.

A Oficina de Geomorfologia ao mesmo tempo que constitui uma atividade prática dentro de uma disciplina é, também, uma metodologia de trabalho didático-pedágogico, em construção, com conteúdos de geomorfologia que possam ser socializados em atividades de extensão universitária, para comunidades situadas em áreas de risco-socioambientais.

\section{Atividade acadêmica:oficina de geomorfologia}

A atividade nomeada de Oficina de Geomorfologia, fundamenta-se em 5 pilares importantes dentro de um ensino-aprendizagem significativo e com enfoque globalizador. A saber: a) situação cotidiana problematizada; b) saberes e conhecimentos integrados; c) relação prática-teoria; d) raciocínio complexo e e) técnica de construção de maquete. Estes são entendidos aqui tanto como reveladores de uma concepção de ensino/aprendizagem, quanto parâmetros que norteiam o desenvolvimento da oficina, conforme apresentado e discutido nos itens seguintes.

Vale destacar que no presente texto, as discussões extrapolam os aspectos vivenciados na Oficina de Geomorfologia e apontam para as possibilidades em situações de aprendizagem fora do universo acadêmico.

\section{Discussão dos pilares da Oficina de Geomorfologia}

a) Situação Cotidiana Problematizada - as áreas de riscos, como um espaço geográfico, podem ser discutidas durante a educação formal e não formal, por meio da ideia, que se nomeia aqui, de Situações Cotidianas Problematizadas - SCP. Estas situações podem ser contempladas a partir de fatos, conceitos e/ou processos que ocorrem no espaço geográfico. A situação cotidiana considerada é, então, considerada como objeto de discussão e/ou investigação. Portanto, definir o objeto que será problematizado constitui o primeiro passo. Esse objeto pode ser indicado por um orientador, quando este tem em mente conceitos e questões que deseja trabalhar e/ou construir com o seu grupo de trabalho (alunos, cursistas, membros de comunidades e outros). Nesse caso, o desenvolvimento do trabalho segue trajetória objetiva e com procedimentos previamente estabelecidos, respeitada a noção de enfoque globalizador. Apesar de diretiva, durante o processo ajustes de objetivos e procedimentos podem ocorrer em função da própria dinâmica que se estabelece entre diferentes sujeitos envolvidos na construção e discussão de um objeto. Quando o objeto a ser discutido é representado e sugerido pelo próprio grupo de trabalho, esse possivelmente surgirá das vivências e experiências particulares. Portanto, a escolha do objeto deve considerar o que seja comum ao coletivo, uma vez que permite a participação de uma maioria. Cada situação de trabalho é única, portanto, não há regra rígida para a definição de um objeto, mas bom senso, amparado na ideia do interesse coletivo e do significativo para os sujeitos. Entre as situações cotidianas problematizadas podem aparecer: Como e por que as casas foram atingidas pelo material da encosta? Toda encosta é uma área de risco para a população? Como e por que as pessoas ocupam as encostas? Desde quando o material começou a descer pela encosta? Como e por que ocorrem os movimentos de massa?

b) Saberes e Conhecimentos integrados - A representação na maquete de um objeto de discussão ou estudo, demanda do sujeito representador pensar na escolha dos elementos a serem representados, o porquê daqueles elementos, a relação entre eles, a escolha da distribuição espacial de cada elemento e as consequências de determinadas escolhas no tempo e no espaço. Nesse processo de escolha, no primeiro momento, afloram o conhecimento prévio e as possíveis vivencias de cada sujeito. Portanto, saberes comuns se somam durante os diálogos sobre o quê e por quê representar. Na existência de impasses e/ou na permanência de concepões errôneas sobre o objeto em estudo e representação, leituras e discussões são orientadas. Dessa maneira, partindo dos conhecimentos que os sujeitos tem, ampliam-se os significados, sejam de um conceito, um fato, uma ideia. Segundo MoreIRA e MASSINI (1982) uma nova informação (conceito, ideia, proposição) adquire significados para o aprendiz através de uma espécie de ancoragem em aspectos relevantes da estrutura cognitiva preexistente do individuo.

c) Relação prática-teoria - O exercício prático da representação demanda do sujeito, também, um exercício teórico, fundamentado tanto nos conhecimentos empírico, quanto no científico, que podem ser buscados sempre que necessário, via estudos, discussões e diálogos. Durante o processo de problematização e representação dúvidas de natureza conceitual podem aparecer, uma vez que a representação constitui um símbolo (significante) de algo (significado). Este algo precisa ser compreendido a fim de o mesmo ser sintetizado 
em uma representação, geralmente simplificada e reduzida. 0 exercício de codificar a realidade ou o conceito possibilita ao sujeito transitar em dimensões diferentes do conhecimento e a trabalhar a própria cognição. Portanto, o exercício cognitivo estabelecido na interação prático-teórico mobiliza o sujeito do papel de expectador para ator de seu conhecimento e de seus questionamentos sobre o objeto posto a partir de situações vividas no e do cotidiano. Nessa abordagem, o significado é o eixo motor de toda a aprendizagem e, a motivação intrínseca da aprendizagem desejada - autoiniciativa - apóia-se no interesse por resolver um problema ( C. SouzA, 2009).

d) Raciocínio complexo - Este compreende trabalhar no âmbito da cognição com diferentes variáveis de conhecimento, do vivido, percebido e concebido, sobre o objeto em estudo, em discussão e representação. 0 objeto mobiliza nos sujeitos saberes, habilidades e procedimentos distintos de maneira simultânea enquanto é pensado e representado. Ocorre, então, a interação de diferentes conhecimentos e habilidades para entender e representar o objeto estudado.

e) Técnica de construção de maquete - A técnica consiste na compilação das curvas de nível da área de interesse e a reprodução das mesmas na folha de isopor ou papelão. Cada molde de isopor é colocado um sobre o outro respeitando a ordem crescente das altitudes (Fot. 1). Depois dos moldes colados e secos, realizam-se, na superfície da maquete, os cortes de taludes, inferem-se os locais onde há ocupação desordenada, cicatrizes erosivas, acúmulo de material que deslocou e outros elementos que se deseja considerar. Nas faces laterais da maquete, representam-se litologia, estrutura e manto de alteração. A interação da técnica com as discussões sobre vivências ou leituras, sobre movimentos de massa, possibilita criar diferentes situações de ocupação de encostas, como moradias, instalação de estradas, atividades minerárias e outros (Fot. 2 e 3 ).

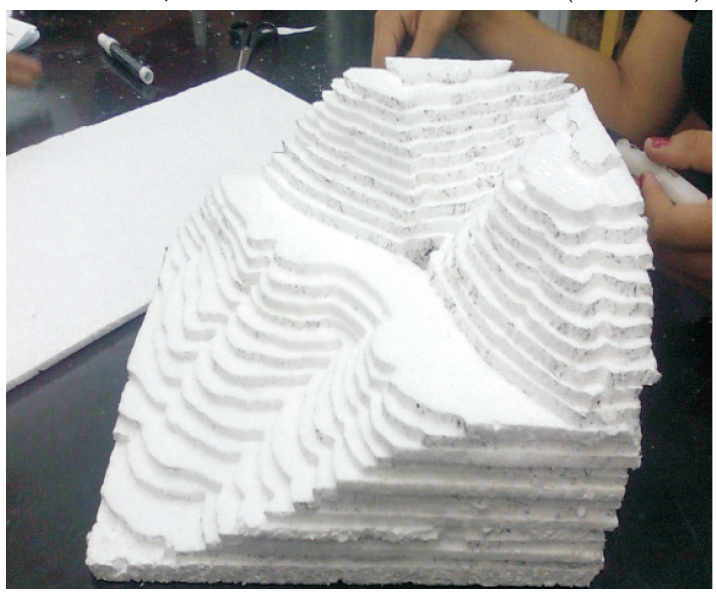

Fot. 1: Montagem da estrutura da maquete a partir das curvas de nível.

Fonte: Oficina de Geomorfologia, 2009 - MORFOLAB.

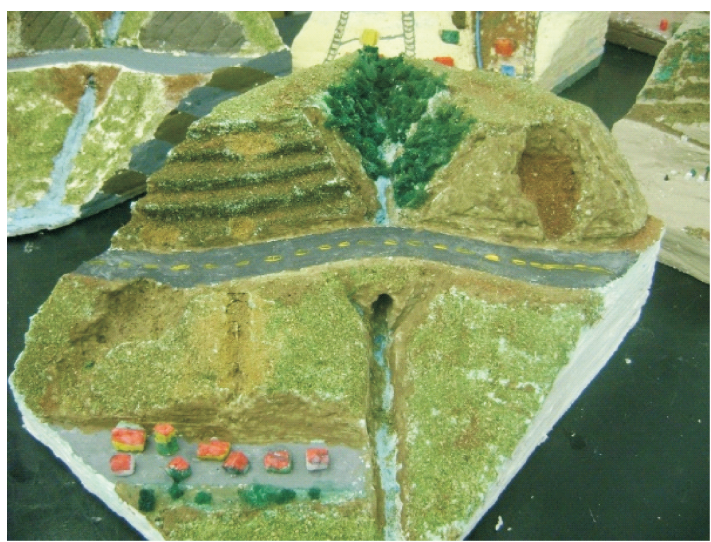

Fot. 2: Encosta com taludes e cicatrizes erosivas. Fonte: Oficina de Geomorfologia, 2009 - MORFOLAB

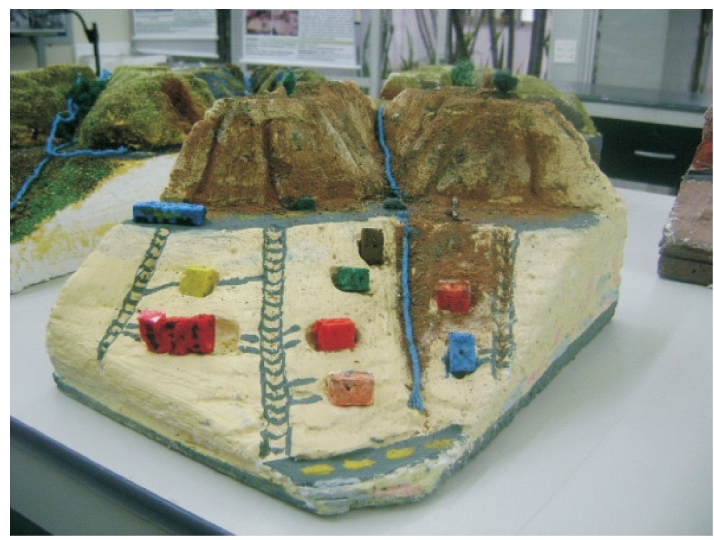

Fot. 3: Encosta com ocupação em área de risco. Fonte: Oficina de Geomorfologia, 2009 - MORFOLAB.

A oficina compreende trabalhos manuais e discussões constantes sobre o assunto representado e sobre a técnica de produção de maquetes a partir de curvas de nível. Para isso são necessários carta ou recorte topográfico da área a ser representada e materiais como: lâminas de isopor ou outro material como papelão $(0,5 \mathrm{~cm})$, tesoura, cola, estilete, vela, cola para isopor, massa corrida, tinta guache, serragem, espuma, palitos e outros.

\section{Parecer de alunos sobre a Oficina de Maquete}

Conhecer as impressões dos sujeitos que participam da atividade prática e teórica constitui um procedimento comum no término das oficinas, bem como a produção de textos. Estes contém uma parte referente à revisão biliográfica, descrição da técnica, discussão dos elementos representados na maquete e autoavaliação. Esta possibilita ao professor orientador ampliar suas impressões sobre o processo de aprendizagem e conhecimento demonstrados por cada sujeito que participou da oficina e, ainda, aprimorar as próximas oficinas. 
De acordo com os alunos (sujeitos), que já participaram da Oficina de Geomorfologia, em 2009,

"A construção da maquete tem muitos pontos positivos, pois ajuda a desenvolvermos o trabalho em equipe, segue todo um passo a passo, desde de pensarmos o que iremos esboçar na maquete, planejamento, levantamento de materiais, distribuição de tarefas, até a finalização da mesma, contribuindo consideravelmente para visualizarmos o conteúdo teórico estudado. Com ela pudemos compreender melhor como se da às ocupações de encosta e os principais fatores condicionantes e desencadeadores dos movimentos de massa, como os aspectos naturais da paisagem e as atividades antrópicas atuam" (Adrienne RodrIGUes, 2009).

“Com a montagem da maquete consegui relacionar com os conceitos dos movimentos de massa lidos nos textos propostos. Esta atividade foi de suma relevância, pois entendi como os movimentos de massa ocorrem ao longo de uma encosta. Aprendi que apesar dos movimentos de massa serem de causa natural, depende de sua geologia, geomorfologia, pedologia e clima. Estes estão diretamente relacionados com as ações antrópicas, que por sua vez alteram a paisagem. A transposição didática fez com que eu reforçasse minhas idéias sobre a importância de um planejamento urbano para que os efeitos da natureza não sejam tão prejudiciais que possa afetar os homens" (Cibele PoRTo, 2009).

"Não sabia que era possível, no caso da nossa maquete, por exemplo, reproduzir em pequena escala os processos erosivos que as empresas mineradoras causam onde se instalam e o que elas deixam na paisagem, quando vão embora. Graças à elaboração de uma 'simples maquete', a idéia do que ocorre pôde ser mais clara” (Frederico Brugnara, 2009).

Vale comentar que a maquete além de facilitar a forma de visualização de como ocorrem os deslizamentos e os processos que antecedem sua ocorrência, ela esclarece, de forma lúdica, como os aspectos geológico, geomorfológicos e antropicos podem acelerar a ocorrência de movimentos [...] bem como as medidas de controles que podem ser aplicadas para evitar danos ao meio ambiente e ao próprio ser humano “ (Luciene de AlmeidA, 2009).

“A criação da maquete funcionou como mais uma descoberta de uma forma de aprendizado, mostrando que é possível explicar além das escritas descobrindo uma nova maneira de aprender e ensinar. Avisualização dos movimentos de massa e a forma como seriam apresentados na maquete fez com que a nossa criatividade fosse aguçada. Aprender a representar através de maquetes parecia algo impraticável, que ao final foi surpreendente em termo de aprendizado acadêmico assegurando uma absorção mais completa do conteúdo que estava sendo passado e que também possibilitou que além dos nossos conhecimentos pudéssemos através dos outros grupos entender outras formas de transposição e representação de maquetes, baseados por diferentes pessoas em leituras de textos sua maioria iguais" (Vaneusa RodRIGUES, 2009).

- A partir da fala dos alunos e das observações in locu, é possível dizer queAs maquetes como representação reduzida e simplificada da superfície do terreno, permitem simular os resultados da relação sociedade e natureza.

- A maquete é também um instrumento que pode favorecer o desenvolvimento de habilidade de visualização espacial.

- Como atividade prática, a oficina possibilita levantar o conhecimento que os sujeitos tem sobre o assunto e ampliar e aplicar a compreensão dos estudos realizados sobre movimentos de massa, através de pesquisa bibliográfica e das aulas dialogadas e expositivas.

- A oficina contribui com vivências e conhecimentos para: a aprendizagem da técnica de representação tridimensional do terreno; pensar e relacionar sociedade e apropriação do relevo; apresentar uma questão a partir da maquete e propor possíveis soluções; ampliar e construir novos conhecimentos e refletir sobre os conteúdos - conceitos, metodologia, recursos e estratégias.

\section{Geomorfologia e Ensino}

O ensino da Geomorfologia tem como um de seus pressupostos levar os estudantes a compreenderem a configuração das formas presentes no espaço, bem como os fatores que explicam os processos presentes em sua dinâmica (Guerra e Cunha, 2001). Uma das maneiras de se trabalhar a questão, por exemplo, dos processos erosivos e seus resultados, é através de representações imagéticas como mapas, blocos diagrama e maquetes (C. SouzA, 2009).

No caso específico do trabalho com maquetes, elas possibilitam uma aprendizagem significativa em função de sua redução e representação de elementos do real que tem significado para o sujeito em processo de conhecimento. A aprendizagem significativa encontrase sob a perspectiva construtivista da aprendizagem. 
Segundo Antoni ZABALA (2007, p. 37), ela ocorre quando os sujeitos da aprendizagem conseguem "atualizar seus esquemas de conhecimento, compará-los com o que é novo, identificar semelhanças e diferenças e integrálas em seus esquemas" que haviam sido construídos previamente. Esse processo ocorre através da mediação do educador.

Sob essa perspectiva, a oficina de maquete busca, através da problematização, tornar os participantes sujeitos do processo de aprendizagem, sendo que ao final é esperado que os mesmos compreendam, de forma mais totalizante, o processo de construção do espaço como resultante da relação entre a sociedade e a natureza em diferentes escalas de complexidade. Mais particularmente, que os participantes visualizem os fatores condicionantes de movimentos de massa que constituem-se em risco para a população.

Uma das maneiras de se minimizar a vulnerabilidade dos grupos sociais, no processo de construção do espaço, é conhecer a representação que esses indivíduos possuem sobre esse mesmo espaço. Pois, segundo Paul Claval (2003,p. 163) “[...] a geografia quer também entender as atitudes dos indivíduos diante da natureza, o sentido que eles dão às suas vidas e os horizontes futuros que eles constroem e que os guiam nas suas existências". Considerando que, "as ideias, habilidades, linguagens, relações em geral, propósitos e significados comuns a um dado grupo social são elaborados e reelaborados a partir da experiência, contatos e descobertas" (R. CoRRÊA, 2003, p.170). Acreditamos que a experiência com a construção da maquete permita a esses sujeitos o conhecimento sobre o terreno (relevo, superfície) que ocupam. Dessa maneira, munindo os sujeitos de instrumentos para que possam compreender a dinâmica de construção do espaço, abre-se a possibilidade de que os mesmos se posicionem frente à influência dos demais agentes de produção do espaço.

Para Roberto Lobato CoRRÊA (1993), o espaço urbano é resultado da interação dos diferentes agentes de produção, quais sejam, os proprietários fundiários, promotores imobiliários, o Estado e os grupos sociais. Esses agentes, ao atuarem na construção desse espaço, produzirão paisagens desiguais, em função da relação de forças presentes no processo. Ao mesmo tempo, o relevo, sob essa perspectiva passa a ter "valor de uso e valor de troca", onde seus diferentes compartimentos (vertentes, topos e fundos de vale) são geralmente ocupados por população de baixa renda - e as áreas menos sujeitas a riscos, como inundação ou movimentos de massa, recebem maior valorização fundiária, sendo ocupadas por populações de melhor poder aquisitivo (L. Pedro, 2009).

Como resultante da relação entre a sociedade e a natureza, via apropriação, os compartimentos geomorfológicos sofrem aceleração dos processos de esculturação. Em seu estudo, Pedro (2009) analisa a proposição de MiLARÉ (1998), para quem a ocupação urbana dos compartimentos geomorfológcos deve contemplar a "análise da morfoestrutura, da morfoescultura, do tipo de solo, da dinâmica hídrica e os riscos associados a sua utilização" (L. Pedro p. 10-11), a fim de se minimizar os impactos negativos para a população.

Locais cujos declives são mais acentuados são locais onde fenômenos, tal como os processos erosivos, podem ocorrer de forma mais rápida e intensa. Na prática docente, através da maquete, grupos puderam relacionar a ocorrência de fenômenos como erosão hídrica, ocasionada pelas chuvas que desencadeia o efeito splash ou erosão por salpicamento e a desagregação e transporte do solo, durante o escoamento superficial (A. Guerra 1999).

Os grupos de trabalho procuraram discutir também a ocupação da encosta por atividade minerária e por residencias. De acordo com as discussões, os grupos colocam que a ocupação da encosta utilizada para a atividade mineradora altera os aspectos geomorfológicos da área uma vez que há necessidade de realizar cortes na vertente para exploração e escoamento do minério, além de construção de barragem de rejeito, comprometendo cursos d água e a remoção total ou parcial da cobertura vegetal expondo o solo a processos erosivos de grande magnitude.

A ocupação residencial na porção jusante da encosta, próxima aos cursos d'água pode sofrer futuros problemas de escorregamentos nos períodos chuvosos devido a umidade excessiva do solo e também a declividade acentuada da área da montante. As casas por estarem situadas sobre cortes de taludes estão expostas a sofrer diretamente com os movimentos de escorregamento, juntamente com queda de árvores e blocos de rochas, pois já estão localizadas em áreas geomorfologicamente frágeis e passam a ser consideradas como área de risco.

Os aspecto geológicos como mergulho das camadas, presença de falhas e fraturas, características litológicas combinados com os aspectos geomorfológicos do local, como extensão e morfologia da vertente, descontinuidade do solo, presença de aterros e lixos, são condicionantes favoráveis aos movimentos de massa.

\section{Alguns conceitos e definições}

Para uma melhor compreensão do tema em estudo é importante conhecer conceitos e definições que são mencionados ao longo deste artigo, como geomorfologia, vertente, encosta, movimentos de massa e áreas de risco.

A geomorfologia é uma ciência que tem como foco de estudo o relevo, buscando compreender sua dinâmica interna e externa, através de uma escala espacial 
geográfica, que pode ser global, regional ou local e, também, temporal - tempo curto e tempo longo (D. Suertegaray, 2002).

A seleção de uma escala espacial e temporal para análise do relevo remete a um procedimento técnico e metodológico. Jurandir Ross (1992), a partir de GeRAsImov (1946) e MECERJAKov (1968), propôs analisá-lo baseandose numa escala de ocorrência do relevo e suas formas, em seis táxons. $01^{\circ}$ táxon - compreende a unidade morfoestrutural; o $2^{\circ}$ táxon - a unidade morfoescultural; - $3^{\circ}$ táxon - unidades morfológicas ou de padrões de formas semelhantes, o $4^{\circ}$ táxon - tipos de forma de relevo; o $5^{\circ}$ táxon - tipos de vertentes e o $6^{\circ}$ táxon formas de processos atuais (J. Ross, 1992).

$\mathrm{Na}$ Oficina de Geomorfologia, trabalhou-se com o $5^{\circ} \mathrm{e}$ $6^{\circ}$ táxons, ou seja, a representação da vertente e as cicatrizes erosivas presentes nas mesmas. 0 estudo das vertentes constitui um dos mais importantes campo da pesquisa geomorfológica onde análises dos processos e formas são considerados (A. ChristofolettI, 1980). Neste contexto, é importante conceituar o termo vertente, tendo em vista que a mesma expressa e explica a evolução do relevo e os processos ocorridos no mesmo, como os movimentos de massa. De acordo com ChristofoletT (1980, p.26), no sentido mais amplo, "vertente significa superfície inclinada, não horizontal" sem apresentar, a princípio, qualquer conotação genética ou locacional. Ela pode ser subaéreas ou marinhas. Jan DyLIK (1968) apud Christofolettı (1980, p. 26) defini vertente como "uma forma tridimensional que foi modelada pelos processos de denudação, atuantes no presente ou no passado, e representando a conexão dinâmica entre o interflúvio e o fundo do vale". A partir dessa definição outras são apresentadas, como "Planos de declives variados que divergem das cristas ou dos interflúvios, enquandrando o vale" (A. Guerra e A. Guerra, 2003, p.634).

Áreas de risco podem ser definidas como sendo o local onde existe a possibilidade de ocorrência de eventos adversos (A. CASTRO, 2003). Sendo assim, esses eventos podem estar ligados a fenômenos naturais e sociais - movimentos de massa, áreas susceptível à erosão, áreas de inundação, áreas de sismos e outros (D. TEófILO; C. SOUZA, 2008).

Os movimentos de massa podem ser definidos como os mais importantes processos geomórficos modeladores da superfície terrestre (J. BigARELLA, 2003). Constituem-se no deslocamento de material solo e rocha vertente abaixo sob a influência da gravidade, sendo desencadeados pela interferência direta de outros meios ou agentes independentes como água, gelo, ar, vento e o próprio homem.

Os movimentos de massa podem ser caracterizados pelas várias formas e processos que possuem. Entre os textos brasileiros, os movimentos de massa denominados de deslizamentos recebem um destaque maior por que, na grande maioria das vezes, ocorrerem em áreas ocupadas pelo homem (N. Fernandes e C. Amaral, 2000), principalmente no ambiente tropical.

Fernandes e Amaral (2000) utilizam a classificação de movimentos de massa do IPT (1991) e do GuIDICINI e Nieble (1984). De acordo com esses autores podemse classificar os tipos de movimentos em: a) corrida, b) escorregamentos (slides e slumps) e c) queda de blocos. 0 material movimentado pode ser composto por uma complexa mistura de solo e rocha ou até mesmo por lixo doméstico. 0 depósito de lixo, nas grandes capitais urbanas, é considerado como parte geológica do Quaternário, tendo um comportamento geomecânico bem definido e associado ao alto risco e acidentes ( $\mathrm{N}$. Fernandes e C. Amaral, 2000).

As corridas (ou fluxos) são caracterizadas por possuir movimentos rápidos e tem uma composição de materiais fluidos e viscosos, por causa da concentração dos fluxos d'água superficiais contínuos que carrega o material terroso. As corridas podem causar enormes danos quando ocorrem juntamente com fatores antrópicos tais como

Construção de residências nas margens dos canais, desvio e bloqueio parcial dos canais naturais para arruamentos, existência de grandes quantidades de material inconsolidado na superfície, decorrentes da atividade de saibreiras, hoje abandonadas (N. Fernandes e C. AmARAL, 2000, p. 134).

Os escorregamentos são de pouco tempo e consistem em movimentos rápidos, com plano de ruptura bem definido permitindo sua segmentação entre o material deslizado e aquele não movimentado. Tendo aspectos longos, apresentando uma relação comprimento-largura cerca de 10:1 (Summerfield, 1991 apud N. Fernandes e C. AMARAL, 2000, p. 136) geralmente eles são separados com base na forma do plano de ruptura e no tipo de material em movimento. Os escorregamentos, considerando o aspecto do plano de ruptura, subdividem-se em: i) translacionais e ii) rotacionais.

Os escorregamentos translacionais ou Slide são comuns e ocorrem em períodos de intensa precipitação caracterizados pela superfície de ruptura com forma planar a qual acompanha descontinuidades mecânicas e/ou hidrológicas existentes no interior do material, causadas por processos geológicos (acamamentos, fraturas e entre outros), geomorfológicos (depósitos de encostas) ou pedológicos (contato entre horizontes, contado solum-saprolitico). Contudo deve-se lembrar que estes processos não estão separados na natureza e atuam juntos no movimento de massa (N. Fernandes e C. AMARAL, 2000). 
Os escorregamentos rotacionais ou slumps são comuns em solos espessos e homogêneos, geralmente oriundos de rochas argilosas (argilitos e folhelhos), são caracterizados por ter uma ruptura curva, côncava para cima dando a característica do movimento rotacional. Estes movimentos podem ser causados por cortes na base desses materiais, podendo ter causas artificiais ou naturais (N. Fernandes e C. Amaral, 2000).

As quedas de blocos são comuns em áreas de alta declividade, com presença de descontinuidades de rochas (fraturas e bandamentos composicionais) e em encostas íngremes de paredões rochosos. São caracterizados pela ação da gravidade que faz com que blocos e/ou lascas de rocha caiem rapidamente em queda livre (GuIDIcINI e Nieble, 1984 apud N. Fernandes e C. Amaral, 2000, p.147). Este material pode formar depósitos de tálus.

Vários fatores relacionados aos processos geológicos/ geomorfológicos podem acarretar condicionantes de escorregamentos. Ainda de acordo com N. Fernandes e C. Amaral (2000), são apontados como condicionantes geológicos e geomorfológicos dos escorregamentos os seguintes aspectos: fraturas, falhas, foliação e/ou bandamento composicional, descontinuidade do solo, morfologia de encosta e depósitos de encosta.

\section{Enfoque globalizador}

0 termo enfoque globalizador é apresentado e discutido por ZABALA (2002). De acordo com esse educador espanhol, o enfoque globalizador considera um conhecimento integral do todo por meio de projetos, estudo do meio, discussão da realidade. O enfoque globalizador está presente nos métodos globalizados. Estes,

"nascem quando o aluno se transforma no protagonista do ensino; quer dizer, quando se produz um deslocamento do fio condutor da educação das matérias ou disciplinas como articuladoras do ensino para o aluno e, portanto, para suas capacidades, interesses e motivações (A. Zabala, 2002, P.144)".

Esse autor pontua como mais significativos para o atual contexto, os métodos: centros de interesse de Decroly; o método de projetos de Kilpatrick; o estudo do meio do MCE (Movimento de Cooperazione Educativa de Italia) e os projetos de trabalho globais.

Aliada a essa ideia, pode-se considerar, também, a concepção de aprendizagem significativa apresentada e defendida por David Ausubel e difundida, no Brasil, por MOREIRA e MASINI (1986), entre outros. A aprendizagem significativa compreende a construção de conhecimento pelo sujeito aprendiz, que parte do seu conhecimento e dos conceitos que já entende. Esses constituem conceitos âncoras que possibilitaram ampliar e construir outros de maneira coerente e significativa para o sujeito em processo de aprendizagem. Este pode ser um conceito, uma noção, um raciocínio, uma teoria ou um fato. Esse conhecimento refere-se aos conteúdos conceituais.

De acordo com MOREIRA e MASSINI (1982) a aprendizagem significativa

[...] processa-se quando o material novo, idéias e informações que apresentam uma estrutura lógica, interagem com conceitos relevantes e inclusivos, claros e disponíveis na estrutura cognitiva, sendo por eles assimilados, contribuindo para sua diferenciação, elaboração e estabilidade. Esta interação constitui, segundo Ausubel (1968), uma experiência consciente, claramente articulada e precisamente diferenciada, que emerge quando sinais, símbolos, conceitos e proposições potencialmente significativos são relacionados à estrutura cognitiva e nela incorporados (MOREIRA $\mathrm{e}$ MAsSINI, 1982, p. 4).

A aprendizagem dos conteúdos conceituais envolve a abordagem de conceitos, fatos e princípios; refere-se à construção ativa das capacidades intelectuais para operar com símbolos, signos, idéias, imagens que permitem representar a realidade. Por exemplo, para aprender sobre bacias hidrográficas o estudante precisa adquirir informações, vivenciar situações em que conceitos como curso d'água, afluente, foz, nascente, divisor de águas estejam presentes. Ou, ainda, compreender os processos presentes nos movimentos de massa requerem o domínio de conceitos como vertente, jusante, montante, encosta, intemperismo, transporte, deposição, escorregamento, deslizamento, talude, interflúvio, talvegue, entre outros. A aprendizagem de conceitos nunca pode ser considerada acabada, uma vez que existe a possibilidade de sua ampliação e aprofundamento à medida que os conhecimentos sejam revistos.

Por outro lado, os procedimentos expressam um saber fazer, que envolve tomar decisões e realizar uma série de ações, de forma ordenada e não aleatória, para atingir uma meta. Ler, desenhar, observar, classificar são alguns desses procedimentos. Assim sendo, ao realizar pesquisa sobre as vertentes ou os cursos d'água de onde mora; construir uma maquete representando a bacia hidrográfica onde mora, bem como os processos que estão presentes aí são alguns exemplos. Para a aprendizagem desses conteúdos é preciso realizar ações; exercitá-las; refletir sobre as mesmas e aplicá-las.

Além dos conteúdos conceituais e procedimentais, os atitudinais também constituem parte dos objetivos a serem tratados através dos métodos globalizados. Eles incluem normas, valores e atitudes no processo do ensino e aprendizagem. Procurar problematizar os 
fatores que definem a relação entre a sociedade e a natureza no processo de ocupação irregular em áreas de risco. Promover o debate em torno das consequências decorrentes dos eventos que atingem certa população ou, propor alternativas para melhor ocupação dos espaços são exemplos de exercício dos conteúdos atitudinais.

\section{Conclusão}

A Oficina de maquete tem mostrado o potencial da mesma no que diz respeito à significação do conhecimento comum e científico; à possibilidade de melhor leitura da realidade; a aproximação dos saberes dos diferentes sujeitos envolvidos na atividade; ao maior envolvimento e participação coletiva das pessoas em processo de aprendizagem de um conteúdo e à maior compreensão dos processos de movimentos de massas e seus condicionantes naturais e antrópicos. Portanto, a oficina de Geomorfologia, como procedimento didáticopedagógico mostrou-se eficiente na construção do entendimento dos processos geomorfológicos, como os movimentos de massa. Diante disso, acreditamos na possibilidade de a mesma metodologia ser desenvolvida com sujeitos residentes em áreas de riscos, durante atividades de extensão universitária, como minicurso/ oficina.

A realização de minicurso/oficina ainda não foi possível acontecer em função da necessidade de se estabelecer parcerias entre a universidade e núcleos comunitários, com subsídios financeiros de orgãos e empresas patrocinadores.

Acreditamos que, o desenvolvimento dessa metodologia com sujeitos de comunidades de áreas de riscos sócioambientais trará experiências novas que ajudarão a repensar a própria metodologia, assim como a olhar para um mesmo objeto com as lentes dos sujeitos que vivenciam os riscos.

Trazer os conteúdos da Geomorfologia para o ensino como caminho para leitura da realidade, do espaço geográfico possibilita, também, uma leitura contemporânea da relação sociedade-natureza.

\section{Referências bibliográficas}

Ausubel, David P. (1968) - Educational psychology: a cognitive view. New York: Holt, Rinehart and Winston.

BigarelLA, João J. (2003) - Estrutura e Origem das paisagens tropicais e subtropicais. Florianópolis: Ed. UFSC, V. 3.

Castro, Antônio Luiz Coimbra de. (2003) - Manual de desastres: Desastres Naturais. Brasília:
Ministério do Planejamento e Orçamento Departamento de Defesa Civil, Vol. 1. Cap.III. Titulo III.

ChristofolettI, Antônio. (1980) - Geomorfologia. São Paulo: Edgar Blücher.

Claval, Paul (2003) - A contribuição Francesa ao Desenvolvimento da Abordagem Cultural na Geografia (p.147-166) IN: CORRÊA, Roberto L. e ROSENDHAL, Zeny (organizadores) (2003) - Introdução à Geografia Cultural. Rio de Janeiro: Bertrand Brasil, 224p.

CorrêA, Roberto L. (1993) - O espaço urbano. $2^{\mathrm{a}}$ edição. São Paulo: Editora Ática, 94p.

CorrêA, Roberto L. (2003) - A Geografia Cultural e o Urbano (p.167- 186). IN: CORRÊA, Roberto L. e ROSENDHAL, Zeny (organizadores) (2003) - Introdução à Geografia Cultural. Rio de Janeiro: Bertrand Brasil, 224p.

DYLIK, Jan. (1968) - Notion de versant en Géomorphologie. Bull. De L'Acad. Polonaise des Sciences, 16(2), p.125-132.

Gerasimov, I. P. Essai d'interpretation geomorphologie du schema general de la structure geologique de l'URSS. Problèmes de Geograhie Physique, v. 12; Tradução AN SSSR. Moscou, 1946.

Guerra, Antônio J. T; CunhA, Sandra B. da. (2000) - Geomorfologia e meio ambiente. Rio de Janeiro: Bertrand Brasil.

Guerra, Antônio T. e Guerra, Antônio J. T. (2003) - Novo dicionário geológico e geomorfológico. Rio de Janeiro: Bertrand Brasil.

Mescerjakov, J. P. (1968) - Les Concepts de Morphoestruture et de Morphoesculture: un nouvel instrument de l'analyse geomorphologique. Annales de Geographie, 77 années, n. 423, Paris, 539-552.

MoreIRA, Marco. A.; MASsinI, Elcie F. S. (1982) Aprendizagem significativa: a teoria de David Ausubel. São Paulo: Moraes.

Paulo, Sérgio de M. (2006) - O Ensino de Geografia e suas Representações Sociais Numa Área de Interesses Ambientais: o caso de Iguape. 2008. Dissertação de Mestrado (Mestrado em Geografia Humana). Universidade de São Paulo, São Paulo, 180p.

Pedro, Leda C. (2009) - Sociedade e Natureza: a interrelação entre ocupação, relevo e os impactos ambientais gerados. XIII Simpósio Brasileiro de Geografia Física Aplicada. Universidade Federal de Viçosa, 06 a 10 de jul., Viçosa- MG, Brasil, 21p. http://www.geo.ufv.br/simposio/ 
simposio/trabalhos/trabalhos_completos/ eixo11/057.pdf (acesso em 15/01/2010).

RibelRo, Manuel João (1995) - A construção de um modelo de análise das vulnerabilidades sociais dos desastres. Uma aplicação à colina do Castelo de S. Jorge.Terrtorium. Lisboa, $n^{\circ} 13$, p.5-24.

Ross, Jurandyr L. S. (1992) - O Registro Cartográfico dos Fatos Geomórficos e a Questão da Taxonomia do Relevo. Revista do Departamento de Geografia. São Paulo: Universidade de São Paulo. 7p.

Suertergaray, Dirce M. A. (2002) - Tempos longos... tempos curtos... na análise da natureza. Geografares. Vitória:UFES, n.3, jun., p.159 - 163.

SouzA, Carla J. de O. (2009) - Geomorfologia no ensino superior: difícil, mas interessante! Por que? Uma discussão a partir dos conhecimentos $e$ das dificuldades entre graduandos de geografia - IGCIUFMG. Belo Horizonte: IGC - UFMG (Tese de doutorado), 2009, 268p.

Summerfield, M. A. Global Geomorphology: an introduction to the Study of Landforms. London: Longman \& Technical, 1991.

Teófilo, Dayse R. de A.; SouzA, Carla J. de O. (2008) Discussão sobre Deslizamento: Casos em Belo Horizonte. Trabalho de Conclusão de Curso (Graduação em Geografia e Análise Ambiental) - Centro Universitário de Belo Horizonte, Belo Horizonte, 25p.

ZabAlA, Antoni (2002) - Enfoque globalizador $e$ pensamento complexo. Porto Alegre: Artmed, $248 \mathrm{p}$.

ZabalA, Antoni (1998) - A prática educativa: como ensinar. Porto Alegre: Artmed, 224p. 